\title{
A MÍDIA ELETRÔNICA E O PERFIL DE ESTUDO DO RESIDENTE MÉDICO
}

\author{
Julia Reimberg*, Silvia M. R. R. Passeri, Fáblo H. Menezes
}

\section{Resumo}

Os médicos residentes têm um grande volume de atividades assistenciais designadas a eles, limitando de modo expressivo a carga horária designada ao ensino teórico, sendo um grande desafio para as instituições adequar o conhecimento necessário nesse período limitado de tempo. Diante disso, o e-learning evidencia-se cada vez mais como uma ferramenta importante nesse contexto. Assim, este estudo de coorte transversal analisou o perfil de estudo e o uso das mídias eletrônicas pelos residentes matriculados em especialidades cirúrgicas por meio de questionários, os quais foram planilhados e analisados pelos softwares SPSS e GraphPad Prism. Houve um índice de 44,76\% de resposta, em que se observou que $87,1 \%$ dos alunos acreditam que intercalar e-learning com o método tradicional de ensino poderia ser interessante para o aprendizado, além de se observar que a maioria dos entrevistados $(61,7 \%)$ ainda prefere estudar por impressos que por mídias eletrônicas.

\section{Palavras-chave:}

Educação médica, ensino, residência médica.

\section{Introdução}

A Residência Médica é baseada no conceito de treinamento em serviço, aliando tanto atividades assistenciais quanto de ensino-aprendizagem. Pela limitação advinda da carga horária e do grande volume de atividades assistenciais designado ao médico residente, a atividade assistencial acaba por representar papel expressivamente majoritário durante a pós graduação, restando pouco tempo às atividades complementares de ensino teórico para consolidação do conhecimento adquirido na prática. Desta forma, as escolas médicas enfrentam atualmente o desafio de transmitir o conhecimento essencial à formação do especialista em um período de tempo limitado de maneira sólida e efetiva. Em meio a isso, o e-learning, definido de modo abrangente como um meio educacional fundamentado no uso da internet, se mostra como ferramenta cada vez mais importante no contexto da Educação Médica atual. Assim, este trabalho teve por objetivo identificar como se caracteriza o uso das mídias eletrônicas pelos residentes e traçar o perfil de estudo do médico residente em Cirurgia Geral.

\section{Resultados e Discussão}

Este estudo de corte transversal analisou o perfil de estudo e caracterizou como se dá o uso das mídias eletrônicas pelos médicos residentes regularmente matriculados em especialidades cirúrgicas através de questionário padronizado, o qual foi aplicado, após aprovação pelo Comitê de Ética e Pesquisa, por meio de entrevista individualaos residentes da área cirúrgica do Hospital de Clínicas da UNICAMP que concordaram em participar do estudo, com índice de resposta de 44,76\%. Para análise estatística foram utilizados os softwares SPSS e GraphPad Prism e a correlação para análise pareada dos dados foi realizada por meio do coeficiente de correlação de Pearson, com nível de significância adotado para os testes estatísticos de $p<0.001$. A partir dos dados, observou-se que $87,2 \%$ dos médicos residentes acreditam que seria interessante o uso associado do e-learning às aulas teóricas, sendo que $78,7 \%$ deles acreditam que as aulas presenciais são essenciais ao aprendizado durante o programa de pós graduação. Além disso, $61,7 \%$ dos alunos relatam preferência pelo uso de material impresso. Essa mesma situação foi observada por Yamsom et al., em estudo que mostrou que $57 \%$ dos alunos de medicina preferiam o uso de recursos impressos, contra $43 \%$ que davam preferência ao material digital. A partir desses dados, é interessante observar a tendência crescente ao uso da tecnologia, já mostrada em 2006 por Leven et al., que cita estudo de Frey P. Et al., de 2000, no qual mostrava uma preferência de $90 \%$ dos alunos de medicina pelo uso de fontes impressas em relação a $10 \%$ que preferiam fontes digitais. Sobre o uso da internet, $45 \%$ dos entrevistados afirmam utilizá-la mais de $3 \mathrm{hs}$. Contudo, $51 \%$ deles relatam dedicar menos de $3 \mathrm{hs}$ semanais ao estudo teórico de Cirurgia, $66 \%$ destinam menos de $3 \mathrm{hs}$ semanais para leitura de livros textos de medicina e $79 \%$ utilizam também menos de 3hs para leitura de artigos científicos. É ainda interessante notar nessa análise que, apesar de $91,5 \%$ dos entrevistados acreditarem que o elearning é um eficiente método de ensino, $68 \%$ acreditam que aulas por videoconferência não são mais interessantes que aulas tradicionais. Os residentes foram também questionados sobre o uso da Plataforma Moodle, pois a UNICAMP utiliza-se dela para apoio ao ensino de Medicina, e foi mostrado que apenas $57,4 \%$ dos alunos já usaram a Plataforma Moodle durante a sua formação.

\section{Conclusões}

Com o estudo conclui-se que os residentes atribuem grande importância à tecnologia para a formação como especialistas, mas não a veem como modo de substituição à metodologia tradicional de ensino e sim como complemento ao processo de ensino-aprendizagem.

\section{Agradecimento}

Os autores agradecem aos residentes de Cirurgia pela participação no estudo.

\footnotetext{
1.AZER, N.; SHI,N.; DE GARA, C.; KAMARLI, S. iBIM-internet-based interactive modules: an easy and interesting learning tool for general surgery residents. Canadian journal of surgery, v. 57, n. 2, p. 31-35, 2014.

2.BAMFORD, R.; COULSTON, J. Effective e-learning in surgical education: the core values underpinning effective e-learning environments and how these may be enhanced for future surgical education. E-cancer medical science, v. 10, p $1-5,2016$.

3.BOTTI, S. H. O; REGO, S. Processo ensino-aprendizagem na residência médica. Revista Brasileira de Educação Médica, v.34, n.2, p. 132-140, 2010. 4.YAMSON, G. C.; APPIAH, A. B.; TSEGAH, M. Electronic vs. Print Resources: A Survey of Perception, Usage and Preferences Among Central University Undergraduate Students. ESJ, v. 14, n. 7, p. 291, 2018.
} 